\title{
Análise das estratégias de educação nutricional contra a obesidade infantil em escolas municipais do interior paraibano
}

\author{
Analysis of nutritional education strategies against childhood obesity in municipal schools \\ of paraíba interior
}
Análisis de estrategias de educación nutricional contra la obesidad infantil en escuelas municipales dentro de paraíba

Waleska Gualberto da Silva ${ }^{1^{\star}}$, Walnara Arnaud Moura Formiga ${ }^{1}$, Rafael Ferreira Lima ${ }^{2}$, Izabela Letícia de Andrade e Silva ${ }^{1}$, Lourena de Melo Almeida" ${ }^{1}$, Gislane de Almeida Linhares ${ }^{1}$, Thiago Alves Viana $^{1}$, Jessilânia Gomes da Silva ${ }^{1}$, Sabrina Bezerra da Silva ${ }^{1}$, Érika Maria Gomes de Araújo Nóbrega ${ }^{3}$.

\section{RESUMO}

Objetivo: O principal objetivo desta pesquisa é analisar o desenvolvimento de estratégias de educação nutricional em escolas municipais de Malta - PB que possam contribuir para prevenção ou controle da obesidade infantil. Métodos: Foi submetido questionário semiestruturado, baseado no questionário desenvolvido por Bezerra KF, et al., 2015, aos professores do Ensino Fundamental I das Escolas Municipais da cidade paraibana de Malta-PB. Os dados foram tabulados pelo programa estatístico SPSS for Windows 21. Resultados: O resultado apontou que mesmo sendo importante prevenir e controlar a obesidade infantil e já serem realizadas estratégias de educação nutricional nas escolas pesquisadas as metodologias abordadas ainda são insuficientes ou pouco eficazes no auxílio à prevenção e controle da Obesidade Infantil, refletindo questões formativas dos professores, recursos tecnológicos e financeiros. Considerações Finais: Para que se efetive o combate à obesidade, estratégias mais específicas, atualizadas e adequadas à realidade infantil de ensino-aprendizagem deveriam ser trabalhadas para surtir o efeito protetor nos escolares.

Palavras-chave: Educação nutricional, Estratégias, Obesidade infantil.

\begin{abstract}
Objective: The main objective of this research is to analyze the development of nutritional education strategies in municipal schools in Malta - PB that can contribute to the prevention or control of childhood obesity. Methods: A semi-structured questionnaire, based on the questionnaire developed by Bezerra KF, et al., 2015, was submitted to teachers of Elementary School I of the Municipal Schools of the Paraíba city of Malta-PB. The data were tabulated by the statistical program SPSS for Windows 21. Results: The result showed that even though it is important to prevent and control childhood obesity and nutritional education strategies are already being carried out in the schools surveyed, the methodologies addressed are still insufficient or ineffective in helping to prevent and control Childhood Obesity, reflecting teacher training issues, technological and financial resources. Final Considerations: In order to combat obesity, more specific, updated and appropriate strategies to the children's reality of teaching and learning should be worked to have a protective effect on schoolchildren.
\end{abstract}

Keywords: Nutritional education, Strategies, Child obesity.

${ }^{1}$ Centro Universtiário de Patos, Patos-PB. *E-mail: waleska.gual@gmail.com

2 Universidade Federal de Campina Grande, Pombal-PB.

3 Universidade Federal da Paraíba, João Pessoa-PB.

SUBMETIDO EM: 4/2020

ACEITO EM: 5/2020

PUBLICADO EM: 5/2020 


\section{RESUMEN}

Objetivo: El objetivo principal de esta investigación es analizar el desarrollo de estrategias de educación nutricional en las escuelas municipales de Malta - PB que pueden contribuir a la prevención y el control de la obesidad infantil. Métodos: Se envió un cuestionario semiestructurado, basado en el cuestionario desarrollado por Bezerra KF, et al., 2015, a los maestros de la Escuela Primaria I de las Escuelas Municipales de la ciudad de Paraíba de Malta-PB. Los datos fueron tabulados por el programa estadístico SPSS para Windows 21. Resultados: El resultado mostró que, aunque es importante prevenir y controlar la obesidad infantil y las estrategias de educación nutricional ya se están llevando a cabo en las escuelas encuestadas, las metodologías abordadas aún son insuficientes o ineficaces para ayudar a prevenir y controlar la obesidad infantil, lo que refleja los problemas de capacitación docente, recursos tecnológicos y financieros. Consideraciones finales: Para combatir la obesidad, se deben trabajar estrategias más específicas, actualizadas y apropiadas a la realidad de la enseñanza y el aprendizaje de los niños para tener un efecto protector en los escolares.

Palabras clave: Educación nutricional, Estrategias, Obesidad infantil.

\section{INTRODUÇÃO}

A Educação Alimentar e Nutricional (EAN) é entendida, dentre muitos de seus conceitos como um conjunto de ações, estratégias e serviços mediante os quais o conhecimento técnico científico da nutrição é dissemindada aos que por meia dela podem ter seus hábitos alimentares modificados, serem melhor instruídos e consequentemente melhoar a qualidade de vida e sáude.

É ainda, de tal forma importante que é vista como uma ação estratégica para assegurar que a Segurança Alimentar e Nutricional (SAN) se consolide, tornando-a numa das diretrizes da Política Nacional de Segurança Alimentar e Nutricional (PNSAN). (MINISTÉRIO DO DESENVOLVIMENTO SOCIAL, 2018).

Com isso, tem-se dado um maior enfoque em ações preventivas e promotoras de saúde, tendo sido publicada em 17 de junho de 2013 a Resolução FNDE no 26 que fortalece um dos eixos do programa, a Educação Alimentar e Nutricional (EAN), ao dedicar uma Seção às ações de EAN, tornando tal diretriz que prima pela Educação Nutricional nas escolas tão necessária quanto qualquer outra medida intervencionista ou emergencial no combate à obesidade e às várias doenças crônicas não transmissíveis que tem nela uma porta de entrada (BRASIL, 2013).

Em 2009, a sansão da Lei 11.947 de 16 de junho trouxe novos avanços para o Programa Nacional de Alimentação Escolar (PNAE),), ainda nesta lei, no seu artigo 2º, são descritas as diretrizes da alimentação escolar, entre elas existe a que determina a Educação Alimentar e Nutricional no âmbito escolar para que componha o currículo e sirva como veículo de promoção da alimentação e práticas saudáveis com interesse à geração de segurança alimentar e nutricional (BRASIL, 2009).

As altas prevalências do excesso de peso, em crianças e adolescentes, verificadas em distintas partes do planeta, reforçam a necessidade da implantação de novas estratégias preventivas e fizeram emergir o importante papel da promoção da atividade física e da educação nutricional ainda na escola, já que essa demonstra ser ambiente favorável para intervenções que envolvam práticas dos temas supracitados (GUERRA PH, et al., 2016).

A escola é o local ideal para a implementação dessas estratégias porque a maioria das crianças passa grande parte do tempo nesse espaço. Além disso, o ambiente escolar tem influência sobre a saúde, pois as escolas fornecem aos estudantes as ferramentas necessárias para que eles entendam as orientações de saúde divulgadas pelos diversos meios de comunicação. A escola também exerce um papel fundamental no desenvolvimento psicológico e emocional das crianças, e pode incluir as informações mais atualizadas sobre saúde no currículo tradicional ou em disciplinas específicas (como educação física ou nutricional) voltadas para a promoção da saúde (RAMOS FP, et al., 2013). 
Inserido neste contexto escolar, temos a figura do docente que é um agente de transformação sociocultural, chamado a atuar dentro das ambiências escolares como um influenciador em potencial podendo gerir os mecanismos de aprendizagem de forma a motivar ou orientar às práticas de seus discentes, de forma que papel importante na formação de cidadãos mais conscientes e com melhor qualidade de vida (TUNES E, et al., 2005).

No entanto, segundo Panato E, et al. (2013), a formação dos professores não os tornam capacitados a lecionar sobre alimentação e nutrição no que tange a Educação Nutricional, o que implica na dificuldade de promoverem uma alimentação saudável, visto que não são obrigados a saberem amplamente sobre o assunto. O que gera, num futuro não tão distante, problemas de saúde advindos de uma alimentação errônea ou desconhecimento nutricional acerca de uma alimentação saudável.

Diante do exposto, o presente estudo objetivou analisar o desenvolvimento de estratégias de educação nutricional que contribuem para prevenção e controle da obesidade infantil em Escolas Municipais de Malta PB.

\section{MÉTODOS}

Trata-se de uma pesquisa de cunho descritivo analítico de abordagem quantitativa. Nela todos os professores da Rede municipal de Ensino Ensino Fundamental I (1을 $\left.5^{a}\right)$ turno manhã e tarde, da rede municipal de ensino de Malta- PB, da zona urbana e rural tiveram questionário sumentido para a coleta dos dados.

Os critérios de inclusão no estudo foram: ser professor e estar ativamente atuante e participante no quadro de docentes, em regência de sala e que aceitando participar da pesquisa tenha assinado o Termo de Consentimento Livre e Esclarecido (TCLE). Foram automaticamente excluídos ou tiveram seu desligamento imediato à pesquisa aqueles que não estiveram ativamente ligados ao corpo de professores, ou de licença ou férias destas escolas municipais.

Os questionários apresentavam questões diretas, optativas que necessitavam de subjetividade do participante e foram confeccionados pelo pesquisador, baseado no referencial teórico da Segurança Alimentar e Nutricional (SAN), o Direito Humano à Alimentação Adequada (DHAA), na Estratégia Intersetorial para Prevenção e Controle da Obesidade - Recomendações para Estados e Munícipios e na Educação Alimentar e Nutricional (EAN) (Brasil, 2014) e adaptado de Bezerra KF, et al., (2015).

Após a prévia assinatura do TCLE, os questionários foram entregues aos professores, que ali estiveram presentes, foi estipulado o período mínimo de meia hora, e máximo de 45 minutos para que os participantes pudessem entregar seus questionários respondidos à pesquisadora. Para aqueles que por motivos superiores não puderam respondê-lo naquele momento do encontro, foi dado o prazo de uma semana para que pudessem entregar o questionário respondido na diretoria da sua respectiva escola, para que fosse armazenado em pasta específica deixada pelo pesquisador, e recolhido em tempo oportuno.

Junto ao questionário se seguiu uma nota de esclarecimento da natureza da pesquisa, sua importância e a necessidade de obter respostas, para que qualquer dúvida fosse então sanada.

Foram realizados um total de quatro encontros deste nível, um para cada Unidade Escolar urbana e um que uniu as duas unidades rurais que já se reuniam comumente para planejamentos pedagógicos mensais. Todos no local da escola, em sala ou área reservada para atividades desta natureza e que proporcionavam a preparação do ambiente. Ao final de cada encontro foi servido um lanche nutritivo como forma de confraternização entre os participantes.

Ao término do período estabelecido para resposta ao questionário, o pesquisador se encarregou de recuperar as pastas contendo os questionários junto às diretorias de cada Unidade Escolar. Foi estabelecido o prazo de mais uma semana para aqueles que estivessem pendentes. Então, ao fim desta semana, foram recolhidos os dos retardatários, submetidos ao programa estatístico SPSS for Windows 21, sendo posteriormente tabulados e analisados. O período de coleta de dados se estendeu pelos meses de agosto a 
setembro de 2016. O projeto foi submetido à avaliação do Comitê de Ética em Pesquisa (CEP) das Faculdades integradas de Patos (FIP), recebendo sua devida aprovação em 19 de agosto de 2016 através do Parecer Consubstanciado de $\mathrm{n}^{0} \mathbf{1 . 6 8 7 . 1 2 4}$ liberando assim a coleta de dados.

\section{RESULTADOS E DISCUSSÃO}

Das cinco escolas municipais nas quais foram realizados os encontros para coleta de dados que a participação foi de $87,5(n=21)$ não havendo nenhum que tendo iniciado a pesquisa tenha desejado dela se afastar. Aqueles que não aceitaram participar ou não concordaram com a pesquisa corresponderam a 8,3\% $(n=2)$. Uma professora $(4,16 \%)$ foi excluída da submissão ao questionário por estar em período de licença, assim como rezavam os critérios de exclusão. Todos os participantes $(n=21)$ eram do sexo feminino, conforme disposto na Tabela 1, abaixo.

Quanto ao nível de escolaridade dos professores apenas um 4,8\% $(n=1)$ não possui nenhuma formação ou outro curso superior que não Pedagogia. Possuem além da graduação especialização na área de Educação 33,3\% ( $n=7)$ e são graduados em Pedagogia 38,1\%, $(n=8)$, ou estão se graduando 19,0\%; $(n=4)$. Aqueles que já são no mínimo pedagogos, com ou sem especialização, e atendem a formação mínima exigida para ensinar é de $71,4 \%(n=15)$. Vemos tamém que é maior o número daqueles professores que dispuseram de menos anos dentro da Unidade Escolar, ficando em desvantagem quando comparados àqueles que apresentam maior tempo, com mais experiência na contextualidade social, histórica e individual da mesma, bem como, dispuseram mais tempo para aplicação e correção de projetos, atividades ou metodologias que incentivem ou modulem os comportamentos dos discentes.

Tabela 1 - Dados de caracterização dos participantes

\begin{tabular}{cccc}
\hline Variáveis & Masculino & $\%$ \\
\hline Sexo & Feminino & 0 & 0 \\
& Professores & 21 & 100 \\
\hline & Ensino Médio Completo & \\
\hline Nível de Escolaridade & Curso Pedagógico Superior Incompleto & 1 & 4,8 \\
& Curso Pedagógico Superior Completo com Especialização na & 4 & 19,0 \\
& área de Educação & 38,1 \\
Tempo de trabalho na & Outro Curso Superior & 33,3 \\
Unidade Escolar Atual & Menor/igual que 5 anos & 1 & 4,8 \\
\hline & Mais que 5 anos e menos que 10 anos & 10 & 47,6 \\
& Mais de 10 anos & 5 & 23,8
\end{tabular}

Fonte: Silva WG, et al., 2020.

Todos os participantes da pesquisa responderam acreditar ser importante trabalhar estes temas em sala de aula com seus alunos, sendo que desses $42,9 \%(n=9)$, disseram já ter desenvolvido alguma atividade a cerca da Alimentação Saudável com uma boa frequência com seus alunos, 52, 4\% ( $n=11)$ ás vezes, e apenas $1(4,8 \%)$ deles disse não ter realizado, como mostra o Gráfico 1, disposto acima, porém com a justificativa que assumiu recentemente o cargo e ainda não dispôs de tempo para fazê-lo, isto é, as atividades são realizadas, todavia não com a frequência esperada para surtir algum efeito na mudança de comportamento, já que esse às vezes pode servir de sinônimo de apenas quando é possível, quando dá. 
Gráfico 1 - Desenvolvimento de alguma atividade a cerca da Alimentação Saudável.

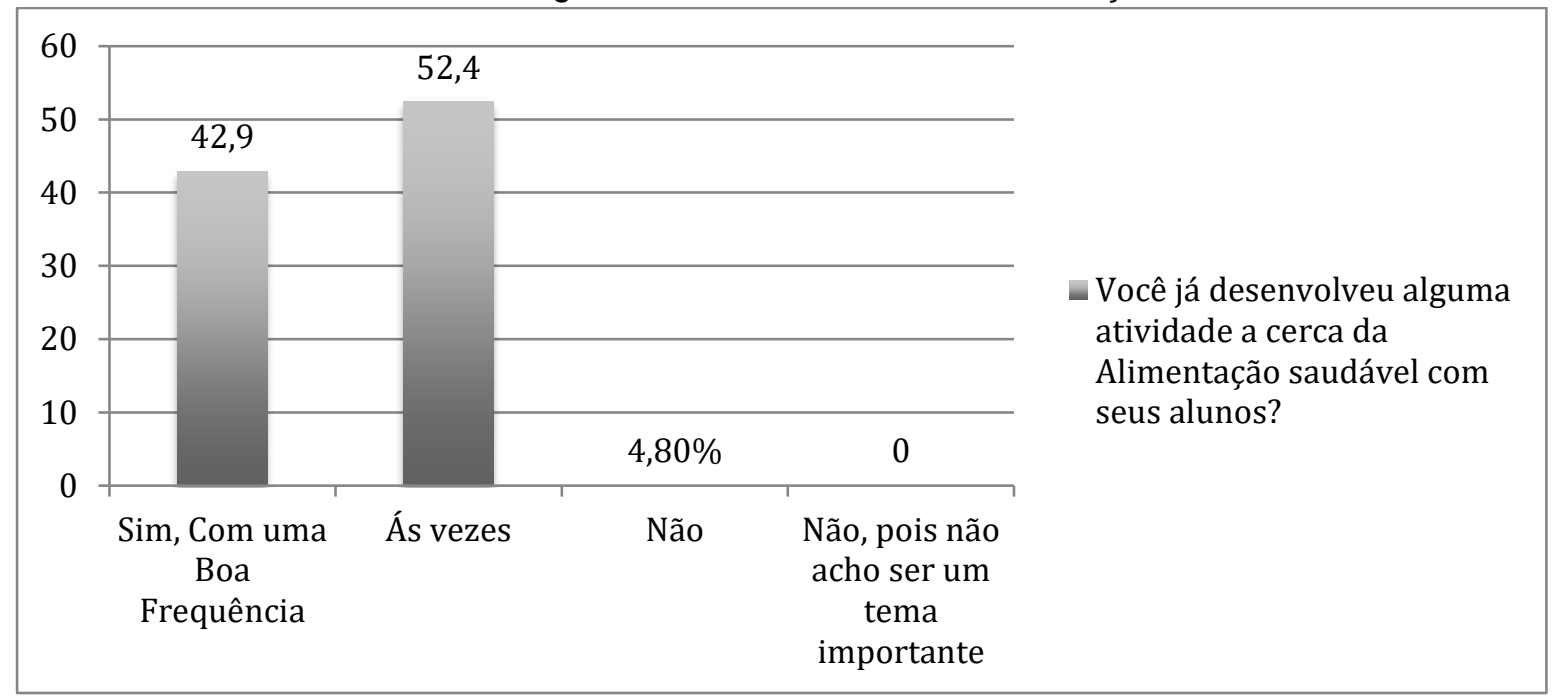

Fonte: Silva WG, et al., 2020.

Rangel CN et al, (2013) em seu estudo percebeu, ainda dentro da descrição das ações educativas, que merendeiras e nutricionistas são vistas como potenciais educadoras e que é considerado necessário desenvolver este potencial. Em paralelo, foi destacado o papel do professor "como mediador da educação alimentar". A "comunidade escolar" aparece como alvo das ações educativas e a necessidade de avalição do alcance e do impacto destas ações foi percebida.

Conforme podemos visualizar no Gráfico 2, disposto abaixo, das várias metodologias passíveis de uso para os professores as mais destacadas foram: Debates e rodas de Conversa $71 \%$, $(n=15)$; Cartazes e murais 66,7\% ( $n=14)$; Aula expositiva 61,9\% ( $n=13)$; Livro didático 54,8\% ( $n=11)$; Elaboração de Receitas 47,6\% $(n=10)$ e Aula dialogada 42,9\% ( $n=9)$. Todas elas são ainda muito ligadas às antigas metodologias utilizadas no processo de ensino e aprendizagem, ainda muito apegadas às simples ferramentas de voz, lousa, papéis e livros, porém, trazem consigo a conquista do diálogo dentro da sala de aula como ferramenta importante na construção dos saberes, sendo a metodologia mais utilizada por $71 \%$ dos participantes. 
Gráfico 2 - Metodologias utilizadas pelos professores para abordagem do tema Alimentação Saudável

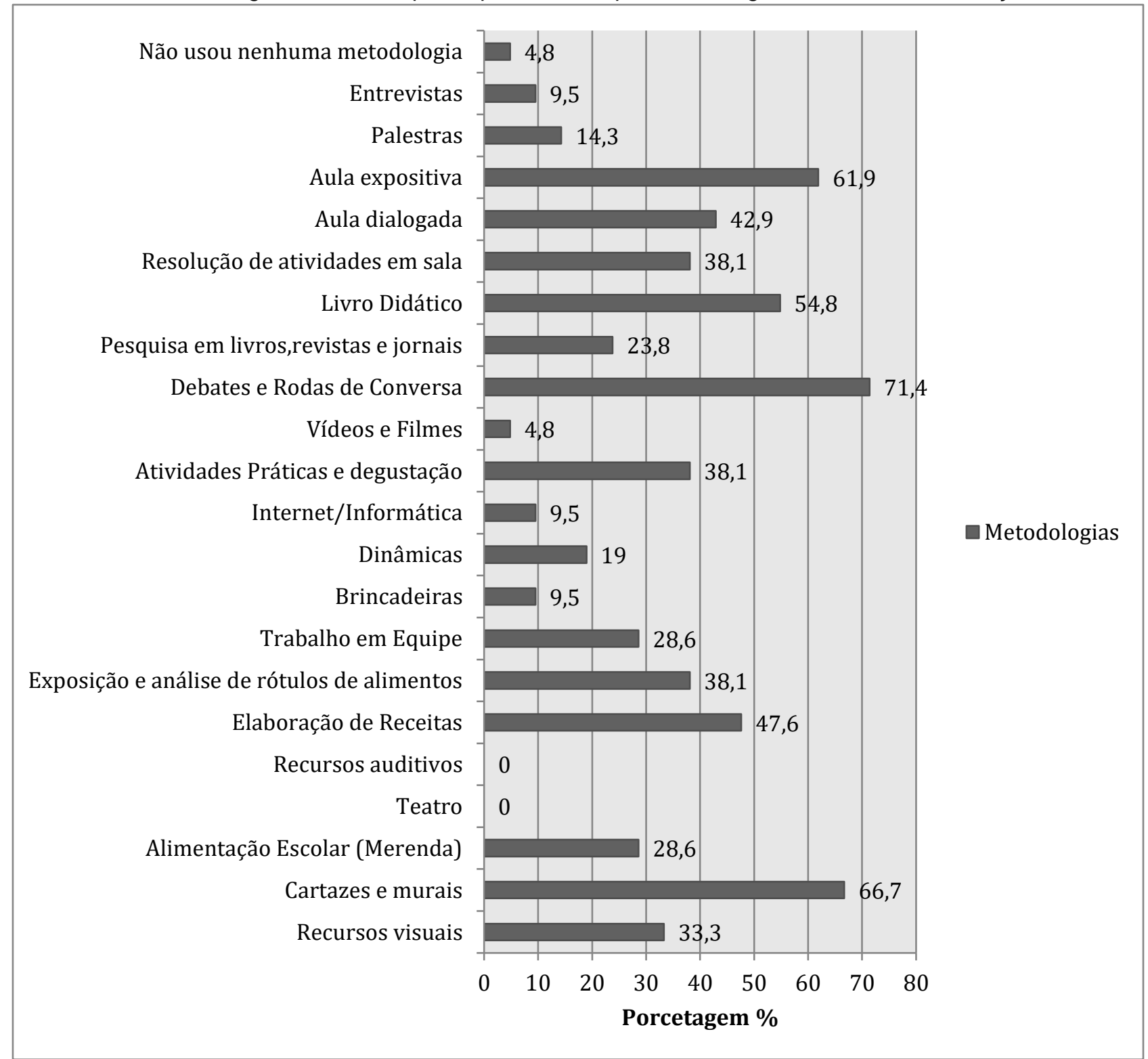

Fonte: Silva WG, et al., 2020.

Metodologias importantes para a exposição de forma mais atrativa e lúdica às crianças e que se mostraram bem utilizadas com percentual de $38,1 \%$, como exposição e análise de rótulos de alimentos e atividades práticas e degustação, nas quais o alimento e mundo alimentar saem dos conceitos e tomam forma a partir de preparações ou gêneros que são observados, pode ser construída de forma prática e participativa por elas mesmas sob orientação de seu professor com colocação de juízo de valores do que é mais saudável ou gostoso nesse processo, e não mais porque outrem diz ser.

De forma geral, a Alimentação Escolar (merenda) e Trabalho em equipe 28,6\% ( $n=6$ ), Pesquisa em livros, revistas e jornais $23,8 \%(n=5)$, assim como Dinâmicas $19 \%(n=4)$, Palestras $(14,3 \%)$ e Brincadeiras e Entrevistas $9,5 \%(n=2)$ mostram pouco uso do lúdico no processo de aprendizagem, além de que poucos professores parecem encontrar nas ferramentas disponíveis dentro do próprio contexto escolar e da infância como maneiras de assimilação de bons hábitos, além de que o enriquecimento através do contato com outrem pareça ser pouco valorizado ou o uso de jogo, como Teixeira QD, et al., (2016) usou para promoção e manutenção de alimentação saudável em uma escola particular no Belo Horizonte-MG, já que apenas 9,5\%, $(n=2)$ mostre-se interessado em Brincadeiras e entrevistas. 
$\mathrm{Na}$ era digital em que tudo se expande através da Informática e Internet apenas 2 professores $(n=9,5 \%)$ disseram abordar a alimentação saudável através destes artifícios, assim como vídeos e filmes 4,8\% ( $n=1)$ mostrando ainda no ambiente escolar uma participação tímida destes meios e aparatos tecnológicos contemporâneos.

Boas metodologias, como teatro e recursos auditivos, que estimulam a capacidade de aprendizado, escuta e interação corporal e comportamental, além de desenvolver o gosto pela leitura e o processo histórico-cultural em que se vive nos alunos não são utilizados pelos docentes. Comparando aos dados encontrados por Bezerra KF, et al., (2015), os professores indicaram em que variar as metodologias para trabalhar os temas junto aos alunos, mas que declararam adotar principalmente pesquisa em livros, jornais e revistas e aulas expositivas. Outras metodologias, como recursos visuais e recursos auditivos, foram pouco usadas também por seus participantes.

Santos LA (2012) evidencia também que, embora haja uma preocupação crescente em relação às bases teórico- metodológicas que regem as ações educativas em alimentação e nutrição, as mesmas também se situam em modelos tradicionais baseados na transmissão de informações com a hegemonia de técnicas como palestras, produção de materiais informativos, dentre outros.

Para Cárdia JAP (2011) a ludicidade é essencial para estimular a vontade de aprender que as crianças vão buscar na escola e que, muitas vezes, é esquecida na rotina de sala de aula, consequentemente, levando o aluno ao fracasso na aprendizagem. Assim como para Walter MS (2013) as atividades lúdicas também atuam na formação da personalidade humana indo além do divertimento propriamente dito, o que assegura seu status quo no processo ensino-aprendizagem na instância da educação infantil. No entanto, como vemos pouca ludicidade é usada pelos professores, e metodologias mais lúdicas e inovadoras ainda são pouco ou não utilizadas, tornando o processo ensino-aprendizagem pouco prazeroso e divertido, bem como um pouco desatualizado.

Ainda nesta perspectiva, o docente contemporâneo deve utilizar os recursos tecnológicos disponíveis, como aliados em sua tarefa de facilitador de aprendizagens, quebrando assim, as barreiras do tradicionalismo e superando os obstáculos, buscando métodos eficazes com o intuito de promover um ensino-aprendizagem de qualidade, segundo Souza DMM e Egídio PT (2016).

Como mostra a Tabela 2, abaixo, todos (100\%) os professores disseram já ter ouvido sobre o termo Obesidade Infantil antes da pesquisa. Desses 90,5\% ( $n=9)$ disseram determinar aquilo que acreditam ser um sério problema de saúde atual, enquanto apenas $9,5 \% \quad(n=2)$ disseram não saber o que este termo determinava. Contudo, foram unânimes ao achar importante desenvolver alguma atividade a cerca da prevenção e controle da Obesidade Infantil com seus alunos.

Quando questionados se já haviam desenvolvido alguma atividade a cerca da Obesidade Infantil com seus alunos, podemos ver que apenas $19,4(n=4)$ disseram que sim, com uma boa frequência, enquanto que $47,6 \%$ $(n=10)$ às vezes e $33,3 \%(n=7)$ não realizou, porém, não foi possível diagnosticar o porquê da não realização. Observando estes dados parece não haver consonância se relacionados às respostas anteriores, indicando que embora seja sim um tema de importância para a saúde e qualidade de vida é ainda negligenciado e abordado com pouca relevância pelos educadores.

Ademais, Maia ER et al, (2012) em estudo com crianças em educação infantil, numa escola privada observou que o emprego de metodologias ativas de ensino-aprendizagem favorece o aprendizado mútuo entre sujeitos e pesquisadores acerca de hábitos alimentares saudáveis e apresenta grande valia ao adequado desenvolvimento infantil. As crianças mostraram-se motivadas a incorporar saberes sobre a nutrição adequada, tendo em vista a redução dos riscos de doenças cardiovasculares. 


\section{Revista Eletrônica Acervo Saúde / Electronic Journal Collection Health ｜ ISSN 2178-2091}

Tabela 2 - Conhecimento e concepções dos Professores a cerca do tema Obesidade Infantil e sua correlação na Vida Escolar

\begin{tabular}{|c|c|c|c|}
\hline Pergunta & Resposta & $\mathbf{F}$ & $\%$ \\
\hline \multirow{2}{*}{ Já tinha ouvido este termo? } & Sim & 21 & 100 \\
\hline & Nunca ouvi nada sobre & - & - \\
\hline \multirow{4}{*}{ O que acha que ele determina? } & Acredito ser um sério problema de Saúde atual & 19 & 90,5 \\
\hline & È um problema de saúde & - & - \\
\hline & Alguma nova doença, talvez. & - & - \\
\hline & Não sei & 2 & 9,5 \\
\hline \multirow{4}{*}{$\begin{array}{l}\text { Acha importante desenvolver alguma atividade a cerca da Prevenção } \\
\qquad \text { e Controle da O.I.? }\end{array}$} & Sim & 21 & 100 \\
\hline & Não & - & - \\
\hline & Talvez & - & - \\
\hline & Não tem opinião & - & - \\
\hline \multirow{4}{*}{ Já Desenvolveu alguma atividade sobre o tema? } & Sim, com uma boa frequência & 4 & 19,6 \\
\hline & Às vezes & 10 & 47,6 \\
\hline & Não & 7 & 33,3 \\
\hline & Não, pois não acho ser um tema importante & - & - \\
\hline \multirow{3}{*}{$\begin{array}{l}\text { Existe correlação entre informação/conhecimento acerca da } \\
\text { Alimentação Saudável e a Incidência de Obesidade Infantil? }\end{array}$} & Sim, acredito estarem diretamente correlacionadas & 20 & 95,2 \\
\hline & Não, não vejo correlação & - & - \\
\hline & Não sei opinar & 1 & 4,8 \\
\hline \multirow{4}{*}{$\begin{array}{l}\text { Acredita ser possível e importante o uso de metodologias inovadoras } \\
\text { de forma interdisciplinar para prevenção e Controle da Obesidade } \\
\text { Infantil inseridos no PPP? }\end{array}$} & Sim & 18 & 85,7 \\
\hline & Não & - & - \\
\hline & Talvez & 3 & 14,3 \\
\hline & Não sei opinar & - & - \\
\hline
\end{tabular}

Fonte: Silva WG, et al., 2020. 
Quanto à crença de que possa existir correlação entre a informação/conhecimento acerca da Alimentação saudável e a incidência de Obesidade Infantil $95,2 \%(n=20)$ dos professores disseram que sim, acreditam estar diretamente relacionados, e apenas um disse não saber opinar. Isso mostra de forma implícita que eles acreditam que se houvesse maior difusão de conhecimento acerca de práticas alimentares saudáveis o número de crianças acometidas pela obesidade poderia diminuir, apresentando a Educação Alimentar e Nutricional como ferramenta importante para a prevenção e controle desta síndrome.

Segundo Bezerra KF, et al. (2015) para que atuem de modo eficiente na promoção da saúde, é fundamental que esses profissionais possuam informações atualizadas sobre saúde, independentemente das disciplinas que ministram, e que apliquem o conteúdo de maneira transversal e interdisciplinar em suas práticas pedagógicas.

Assim $85,7 \%$ ( $n=18)$ dos professores acredita sim ser possível e importante o uso de metodologias pedagógicas inovadoras de forma interdisciplinar que atuem na prevenção e controle da Obesidade Infantil inseridos no Plano Político Pedagógico, e apenas 14,3\% $(n=3)$ responderam talvez.

Para Santos VE, (2013) o reconhecimento da importância de estudos e ações que promovam a saúde e que desenvolvam métodos preventivos da obesidade na infância é visível, pois essa fase da vida é de suma importância para a estruturação de comportamentos, atitudes e hábitos. Além de visíveis repercussões da obesidade na saúde e suas associações com importantes causas de morbimortalidade.

Da mesma forma, Santos AM e Sherer PT (2012) verificaram que num primeiro momento a obesidade era uma questão refletida exclusivamente na área da saúde, e na sequência foi sendo ampliada para outros campos de discussão, especialmente o da educação e do direito.

Corroborando tais fatos, Pimenta TAM, et al. (2015) acreditam que Políticas públicas e ações intersetoriais que estimulem, apoiem e mantenham padrões saudáveis de alimentação e atividade, ou que informem e eduquem, como a Política Nacional de Alimentação e Nutrição (PNAN), Política Nacional Promoção à Saúde (PNPS) e o Plano Intersetorial de Prevenção e Controle da Obesidade (Brasil, 2014), são sinais responsórios à gravidade do problema.

Não obstante, é também defendido por eles, ser necessário um grande investimento por parte do poder público no enfrentamento da obesidade. $E$ isso, por meio de uma consistente e estruturada articulação das políticas intersetoriais e de forma a afirmar sempre a responsabilidade pública diante destas ações.

No questionário, foram elencados temas inerentes à Alimentação e Nutrição que os educadores poderiam ter desenvolvido estratégias educacionais, conforme o disposto na Tabela 3, abaixo, onde mais de uma opção de tema poderia ser assinalada.

O tema Higiene dos alimentos abordado por 90,5\% $(n=19)$ das assinalações, enfatiza o apreço a segurança microbiológica e sanitária devida aos alimentos, porém, pode insinuar que há maior preocupação com a questão sanitária do que com outros temas que apresentam a qualidade e as características nutricionais dos mesmos, como temas Alimentos bem nutritivos com 52,4\% ( $n=11)$, e o Vitaminas e Minerais $42,9 \%,(n=9)$.

Temas como A importância da alimentação e O que é uma boa alimentação, ambos com $81 \%(n=17)$ de abordagem e De Onde vêm os alimentos $71,4 \%(n=15)$ são importantes para que elas conheçam as etapas de produção do alimento, expandindo seus horizontes alimentares, culturais e geográficos além de orientar para um consumo consciente e sustentável.

Outros temas também determinantes para formação de hábitos saudáveis e consequente contribuição para prevenção e controle da obesidade Infantil que direcionam as crianças sobre como são divididos os alimentos nutricionalmente, quais devam ser suas porções diárias como: pirrâmide alimentar, alimentos fornecedores de energia 38,1\%, $(n=8)$, carência e excesso de alimento $33,3 \%,(n=7)$ e nada de exageros $28,6 \%$, $(n=6)$ são ainda timidamente veiculados nas salas de aula, prejudicando a formação e conhecimento nutricional das crianças além de não desenvolver nelas o entendimento sobre a saciabilidade e seu valor para o equilíbrio alimentar e corporal. 
Tabela 3 - Temas inerentes à alimentação e nutrição abordados pelos professores.

\begin{tabular}{ccc}
\hline Temas & F & $\%$ \\
\hline A importância da alimentação & 17 & 81 \\
O que é uma boa alimentação & 17 & 81 \\
Vitaminas e minerais & 9 & 42,9 \\
Solo fértil, alimento mais saudável & 5 & 23,8 \\
Alimentos bem nutritivos & 11 & 52,4 \\
Higiene dos alimentos & 19 & 90,5 \\
De onde vêm os alimentos & 15 & 71,4 \\
Grupos Alimentares (pirâmide) & 4 & 19,0 \\
Nada de exageros & 6 & 28,6 \\
Alimentos fornecedores de energia & 8 & 38,1 \\
Alimentos construtores & 4 & 19,0 \\
Carência e excesso de alimento & 7 & 33,3 \\
Não desenvolvi nenhuma estratégia & 1 & 4,8 \\
\hline
\end{tabular}

Fonte: Silva WG, et al., 2020.

Bezerra KF, et al. (2015) que submeteram de forma pioneira um questionário com a mesma lista de temas dispostos na Tabela 3 acima, destacam de forma enfática a notoriedade de que dispõem tais temas no contexto da educação escolar para formação de hábitos alimentares mais saudáveis, descrevendo ainda que há temas valiosos que não eram bem trabalhados, dentre estes destacam-se aqueles que desenvolveriam nas crianças o entendimento acerca de porções, o papel e classificação de micro e macronutrientes, questões envolvidas no entendimento da saciedade e equilíbrio alimentar que configuram conhecimentos básicos necessários para que uma consciência alimentar e dietética seja formada.

A partir daí é possível notar que mesmo dizendo ser importante prevenir e controlar a obesidade infantil por meio de estratégias pedagógicas, muitos professores ainda não se utilizam de meios corretos de prevenção, além de mostrarem que na prática os recursos que mais usam, assim como os temas não atuam instintivamente na direção do combate à Obesidade Infantil.

\section{CONSIDERAÇÕES FINAIS}

Os achados demonstram que apesar de estratégias de educação nutricional serem realizadas, prevalece ainda, o uso de metodologias obsoletas e que desconversam com correntes pedagógicas mais atuais que valorizam o diálogo, o lúdico e a preocupação com o bem estar social, físico e emocional no processo ensinoaprendizagem como um todo, e que permitem que temas como o abordado no presente estudo ganhem espaço e importância dentro do ambiente escolar.Fica claro, também, que estratégias e temas específicos deveriam ser melhor trabalhados para surtir o efeito protetor nos escolares de combate efetivo à obesidade. Por fim, este estudo permitiu destacar aos professores, diretores e coordenadores a importância da EAN no ambiente escolar, propondo de forma indireta a inserção da mesma no Projeto Político Pedagógico de suas escolas.

\section{REFERÊNCIAS}

1. BEZERRA KF, et al. Conhecimento e abordagem sobre alimentação saudável por professores do ensino fundamental. Demetra: Alimentação, Nutrição \& Saúde. 2015; 10(1):119-131.

2. BRASIL, Fundo Nacional de Desenvolvimento da Educação. Lei 11.947 de 06 de Junho de 2009. Dispõe sobre o atendimento da alimentação escolar e do Programa Dinheiro Direto na Escola aos alunos da educação básica.

3. BRASIL, Ministério da Educação. Fundo Nacional de Desenvolvimento da Educação. Resolução no 26 , de 17 de junho de 2013. Dispõe sobre o atendimento da alimentação escolar aos alunos da educação básica no âmbito do Programa Nacional de Alimentação Escolar - PNAE.

4. BRASIL, Ministério do Desenvolvimento Social e Combate à Fome. Câmara Interministerial de Segurança Alimentar e Nutricional. Estratégia Intersetorial de Prevenção e Controle da Obesidade: Recomendações para Estados e Municípios. Maio 2014a. 
5. BRASIL, Ministério do Desenvolvimento Social e Combate à Fome. Câmara Interministerial de Segurança Alimentar e Nutricional. Estratégia Intersetorial de Prevenção e Controle da Obesidade: Promovendo modos de vida e Alimentação Adequada e Saudável para a população Brasileira. Setembro 2014b.

6. BRASIL, Fundo Nacional de Desenvolvimento da Educação. Programa Nacional de Alimentação Escolar: Dados sobre o programa. Maio 2016.

7. CÁRDIA JAP. A importância da presença do lúdico e da brincadeira nas séries Iniciais: um relato de pesquisa. Revista Eletrônica de Educação. 2011; 9(1): 2011.

8. GUERRA PH, et al. A atividade física e a educação nutricional no ambiente escolar visando a prevenção da obesidade infantil: evidências de revisões sistemáticas. Journal Pediatria. 2016; 92(1):15-23.

9. MAIA ER, et al. Validação de metodologias ativas de ensino-aprendizagem na promoção da saúde alimentar infantil. Rev. Nutr. 2012; 25(1):79-88.

10. PANATO $\mathrm{E}$, et al. Nível de Conhecimento dos professores do ensino fundamental e médio quanto à educação nutricional. Nutrição Brasil. 2013; 12(3): 136-140.

11. PIMENTA TAM, et al. Políticas Públicas de Intervenção na Obesidade Infantil no Brasil: Uma Breve Análise da Política Nacional de Alimentação e Nutrição e Política Nacional de Promoção da Saúde. UNOPAR, Cient. Ciênc. Biol. Saúde. 2015; 17(2): 136-46.

12. RAMOS FP, et al. Educação alimentar e nutricional em escolares: uma revisão de literatura. Rio de Janeiro. Cadernos de Saúde Pública. 2013; 29(11): 2147-2167.

13. RANGEL CN et al. Relações entre o Programa Nacional de Alimentação Escolar e a Educação Alimentar e Nutricional: Discutindo a Produção Científica e o Papel da Comunidade Escolar. Ensino, Saúde e Ambiente. 2013; 6(3): $142-161$.

14. SANTOS AM, SCHERER PT. Política alimentar brasileira: fome e obesidade, uma história de carências. Textos Contextos. 2012; 11(1): 92-105.

15. SANTOS LA. O fazer educação alimentar e nutricional: algumas contribuições para reflexão. Revista Ciências \& Saúde Coletiva. 2012; 17(2): 453-462.

16. SANTOS VE. A prática de hábitos saudáveis na escola: atividade física, alimentação e controle de peso corporal infantil. Arquimeres, 55 p. 2013.

17. SCINTA W. Bounce: A Weight-Loss Doctor's Plan for a Happier, Healthier, and Slimmer Child. ed. 1, Fayetteville, Nova York, Medical Weight Loss ofNew York, PLLC, 234p., 2013.

18. SOUSA DMM, EGÍDIO IV. Avaliação dos docentes e futuros docentes, quanto ao conhecimento e utilização de mídias interativas nas práticas pedagógicas. HOLOS. 2016; 32(1): 55-68.

19. TEIXEIRA QD, et al. O lúdico no ambiente escolar: utilização de jogo para promoção e manutenção da alimentação saudável em uma escola particular da região metropolitana de Belo Horizonte. Revista Tecer. 2016; 9(16): 44-56.

20. TUNES E, et al. O professor e o Ato de Ensinar. Cadernos de Pesquisa. 2005; 35 (126): 689-698.

21. WALTER MS. Atuação lúdico-metodológica dos professores da educação infantil das Escolas da rede pública da zona urbana do município de Floriano - Piauí: Perspectiva didática. Revista do Plano Nacional de Formação de Professores da Educação Básica. 2013; 1(1):130-139. 